\title{
Influence of trust in institutions on public acceptance of nuclear power from a historical context across nuclear countries
}

\author{
P. Mlejnkova \& E. Patelli \\ Institute of Risk and Uncertainty, University of Liverpool, United Kingdom \\ C. Grundy \& Z. Hodgson \\ National Nuclear Laboratory, United Kingdom
}

\begin{abstract}
Several studies have tried to determine what is behind peoples' attitudes to different energy sources and their overall rather negative opinion on nuclear power. The issue of public perception of nuclear power has been going on for decades. But recently with the support of UK governmental nuclear industrial strategy to promote and support nuclear growth it gained even greater interest. Nuclear power is negatively influenced by events from the past such as nuclear accidents and connection of nuclear power with cold war and the use of nuclear bombs. As one of many other factors, the level of trust in authorities is perceived to influence the opposition or support for nuclear power. This study aims to analyze data on trust in four main institutions (government, businesses, media and non-governmental organizations) from a historical perspective in several nuclear countries and find evidence for previous statement. Structural Equation Modelling and Multiple Regression Analysis were used to analyze data and results were compared. Structural Equation modeling is known to be a technique for large samples and did not provide very meaningful results. Multiple regression analysis did not prove that combination of independent variables is significant predictor of support for nuclear power although around 55\% of variance in support for nuclear was explained in UK as well as USA case. Large sample size is required to authenticate model and obtain more robust results. It is likely that Multiple Regression analysis will be used for future data analysis when more data are obtained and results will be compared.
\end{abstract}

\section{INTRODUCTION}

Nuclear power is regarded as an important player in the future decarbonisation of global energy needs. As public support for nuclear power varies year by year from country to country, it is not always easy to find the necessary public support for new build that would be needed. With the UK aging fleet of nuclear power plants a communication strategy is needed to support the necessary new build. In the unfortunate scenario of strong opposition to nuclear power, it is likely that $\mathrm{UK}$ will not comply with its $\mathrm{CO}_{2}$ emission reduction commitments or will risk insufficient power supply and blackouts. Efforts to communicate the advantages of nuclear power are ongoing but do not seem to have positive outcomes. To understand people's attitude towards nuclear power, several studies were conducted, focusing on wide range of issues that can influence public opinion. Kim, Kim and Kim (2014) investigated the effects of knowledge, trust, risk and benefit related factor on public acceptance of nuclear power across
19 countries. Finding that countries with higher level of knowledge of nuclear inspection and lower level of perceived risk of terror are more likely to strongly accept nuclear power. It was also found that that electricity generation is the most effective benefit for enhancing the level of public acceptance of nuclear power and trust in inspection authorities has a positive effect on the probability of reluctant acceptance. A study by Liu, Zhang and Kidd (2008) established correlation coefficients for several factors affecting public acceptance in China. They discovered that opinions on the benefit to power supply, the safety judgement on nuclear power plants, the trust in experts and benefit to environment protection are more influential in the public acceptance of nuclear power then other investigated factors. Public perception of design options for new nuclear plants was investigated by Goodfellow et al., (2015). The study suggests that the general public are willing and able to express 
preferences for design aspects of nuclear power plants and that meaningful information can be obtained to inform designers. The authors argue that involving the public in the design of nuclear power plants is an important aspect of a more transparent, participatory approach intended to improve trust in the governance of future energy supply options. Public opinion on nuclear power as a solution to climate change mitigation was studied by Pidgeon, Lorenzoni and Poortinga (2008). The outcome is that higher proportions of the British public are prepared to accept nuclear power if they believe it contributes to climate change mitigation, but very few actively preferring this over renewable option when given the choice. A paper by Peters, Covello and McCallum (1997) confirmed their hypothesis on perception of trust and credibility in environmental risk communication, founding that set of three main determinants - knowledge and expertise, honesty and openness, and concern and care - accounted for a significant amount of the variation in perception of trust and credibility. Based on the outcomes of the mentioned works and other studies, the focus was aimed on closer investigation of the relationship between trust in institutions and support for nuclear power. The rationale behind this research is to understand what is influencing public opinion in nuclear related matters to support future new build. The argument is that trust in institutions influences public attitude towards nuclear power. The model is then broken down to analyse which institution, whether Government, Business, Media or Nongovernmental organisations (NGO's) has biggest influence on public attitude. It is a longitudinal study based on annual data from world polling companies.

\subsection{Objective}

This study seeks to evaluate the effect of trust in authorities on public support for nuclear power in UK and USA. Structural Equation modelling technique was used to test model fit and evaluate the significance of latent variable Trust in Institutions on Support for Nuclear power. The effect of combination of all four independent variables on Support for nuclear power was also evaluated with Multiple Regression Analysis. Results for both countries are compared.

The hypothesis being tested is that trust in institutions has no influence on public support for nuclear power.

\section{METHODOLOGY}

\subsection{Data}

Data from annual Edelman barometer study on trust in institutions between years 2001 and 2016 were taken as a basis for this study (Edelman, 2016).
There were approximately 450 college educated people aged 35-65 years, providing answer to a phone survey in the US and approximately 200 in the UK. The institutions taken into account for this study are Government, Media, Businesses and NGO's. The effect of trust in institutions on data on public attitude for nuclear power was investigated. Data on public attitude were acquired from several national studies for as many years as available. Data on support for nuclear power in the UK between years 2002-2011 are data from Ipsos Mori research company (Ipsos-mori.com, 2011), 2013-2015 data were taken from Department for Energy and Climate change (DECC) quarterly survey (The Guardian, 2015), missing data were replaced with mean value. Data on support for nuclear power in the USA were taken from Gallup - an international polling and analytics company. Their annual poll can be found at (Gallup, 2015). Missing data were again replaced with a mean value.

\subsection{Structural Equation Modelling (SEM)}

Structural Equation modelling is a confirmatory rather than exploratory technique used in social sciences. SEM includes confirmatory factor analysis, path analysis, partial least squares path analysis, LISREL and latent growth modelling. SEM analysis focuses on latent constructs - the relationship between latent variables (latent variables are not directly measured but explained by two or more observed variables). In this case the latent variable being investigated is Trust in Institutions, which is explained by four observed variables Trust in Government, Trust in Businesses, Trust in NGO's and Trust in Media. The dependent variable in this model is Support for Nuclear power. The model structure is shown in Figure 1. The tested model is the Effect of Trust in Institutions on Support for Nuclear power. AMOS software was used for model testing.

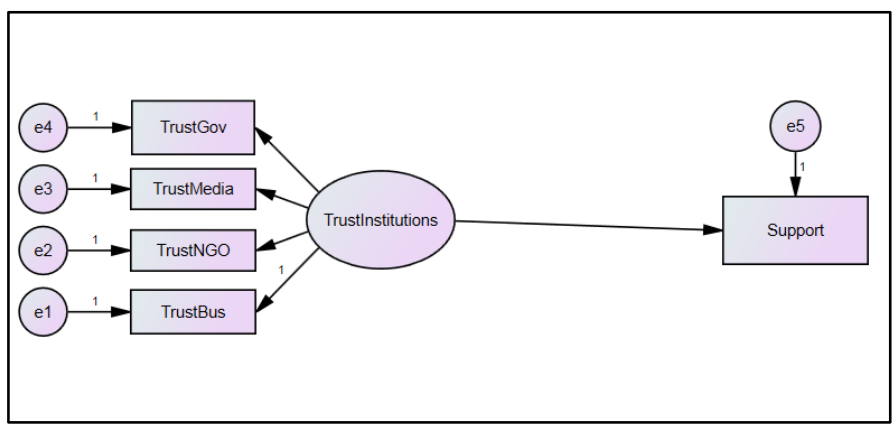

Figure 1. The general hypothesized model for support of nuclear power.

\subsection{Multiple Regression Analysis}

Multiple Linear Regression analysis is used to analyse model with one dependent and two or more independent variables. The variable whose value is to be predicted is known as the dependent variable 
and the ones whose known values are used for prediction are known as independent (exploratory) variables. General multiple regression equation is given by:

$$
Y=b_{0}+b_{1} x_{1}+b_{2} x_{2}+\cdots+b_{n} x_{n}
$$

Where $b_{0}, b_{2}, . ., b_{n}$ are regression coefficients and are analogous to the slope. Multiple Linear Regression was used as a method to evaluate the model and level of significance of combination of all independent variables (trust in Government, Trust in Businesses, Trust in Media and Trust in NGO's) on dependent variable (Support for Nuclear power) and to estimate the level of significance of each independent variable on the dependent variable. Similarities between countries were also evaluated.

\section{RESULTS}

\subsection{SEM results}

UK results

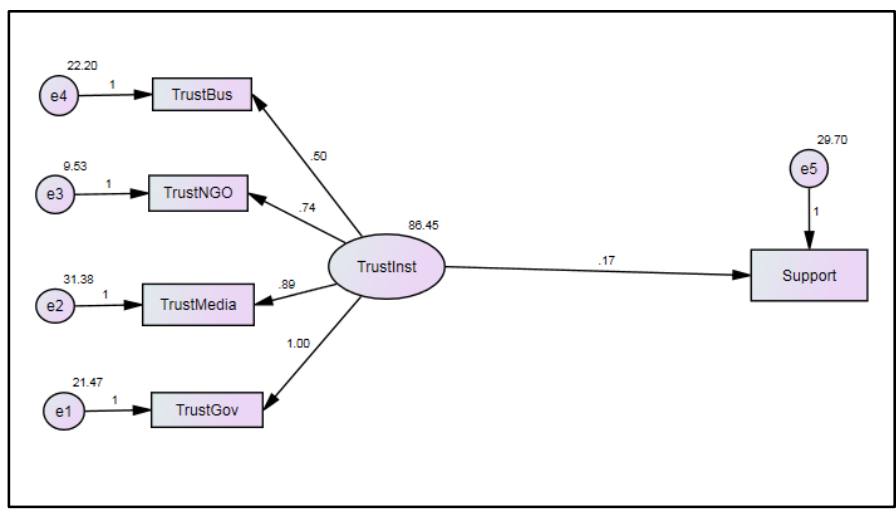

Figure 2. The hypothesized model for support of nuclear power in the UK with standardized path coefficients.

The proposed model for UK proved to be an acceptable fit with normed chi-squared value of 2.271. Other modification indices proved a bad fit with Goodness of Fit Index $(\mathrm{GFI})=.823$ and Adjusted Goodness of Fit Index $(\mathrm{AGFI})=.468$. GFI and AGFI are affected by sample and therefore the used small sample could negatively affect the fit. Comparative Fit Index (CFI) also shows a bad fit with value .828 as well Root Mean Square Error of Approximation (RMSEA) $=.313$ with 90\% confidence intervals of .044 and .558. The direct effect of trust in institutions on support for nuclear power was insignificant (unstandardized coefficient $=.173, \mathrm{p}=.312$ ). For guidelines for determining model fit see Hooper, Coughlan \& Mullen (2008). After first results from a model fitting, more data were collected to improve the model fit. Additional observed variable explaining the Support for nuclear was added in the model. This variable shows the support for nuclear new build in the UK for years 2002-2015.

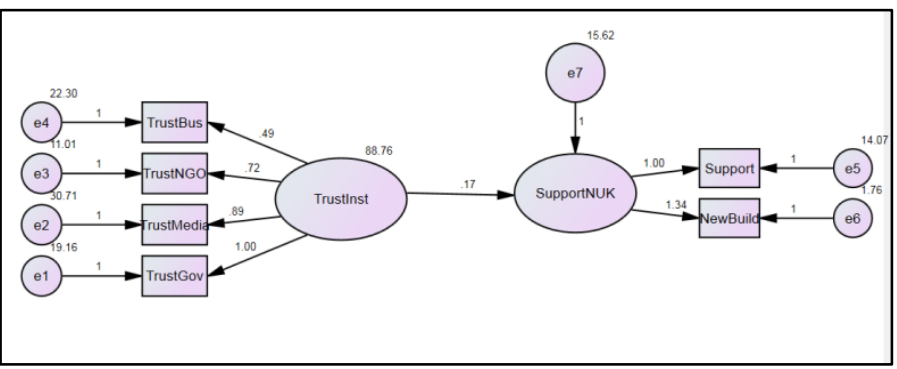

Figure 3. The modified model for support of nuclear power in the UK with standardized path coefficients.

The modified model proved to be a better fit then the original model with normed chi-squared value of 1.908, which shows a good fit. Other indices still indicate still quite poor fit with GFI $=.797$, AGFI $=$ $.467, \mathrm{CFI}=.844$ and $\mathrm{RMSEA}=.264$ with $90 \%$ confidence intervals of .000 and .464 . The direct effect of trust in institutions on support for nuclear power was insignificant (unstandardized coefficient $=.171, \mathrm{p}=0.311$ ) (Hooper, Coughlan \& Mullen, 2008).

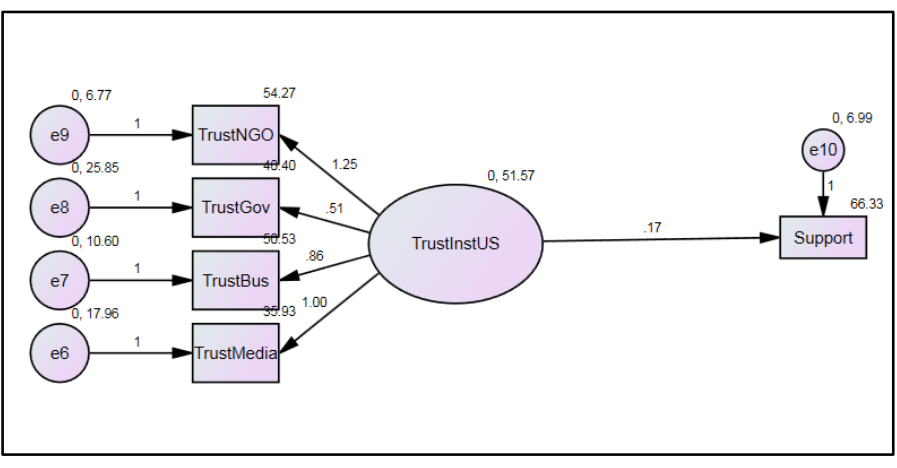

\section{USA results}

Figure 4. The hypothesized model for support of nuclear power in the USA with standardized path coefficients.

The proposed model for USA proved to be a good fit with normed chi-squared value of 1.192. Other indices show a better fit then in a UK case. CFI value .972 proves to be a good fit, RMSEA acceptable with .109 and $90 \%$ confidence intervals of .000 and .378. The direct effect of trust in institutions on support for nuclear power was again insignificant (unstandardized coefficient $=.170, \mathrm{p}=$ 0.102) (Hooper, Coughlan \& Mullen, 2008). Additional data in second dependent observed variable for USA were not available and therefore second model could not be tested.

\subsection{Multiple Linear Regression results}

Results for Multiple Linear regression were obtained in RStudio. 


\section{UK results}

The overall relationship of the UK data can be seen figure 5. Multicollinearity was not found between variables, the correlation coefficients between independent variables are displayed in table 1.

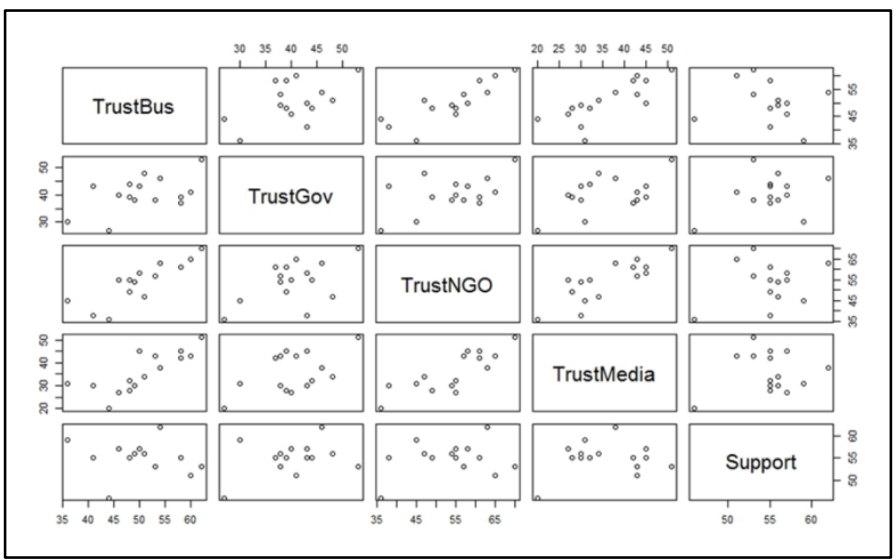

Figure 5. Scatterplots of correlations between UK variables.

Table 1. Correlation coefficients of UK independent variables.

\begin{tabular}{lccc}
\hline & TrustGov & TrustBus & TrustNGO \\
\hline TrustGov & - & - & - \\
TrustBus & -0.16 & - & - \\
TrustNGO & -0.45 & -0.31 & - \\
TrustMedia & -0.37 & -0.07 & -0.34 \\
\hline
\end{tabular}

The results of the multiple regression for UK data indicated that the four predictors explained $60.8 \%$ of the variance in dependent variable $\left(R^{2}=0.608\right.$ and adjusted $\left.\mathrm{R}^{2}=0.433\right)$. But the significance of was not confirmed $(F(4,9)=3.485$ and $p=0.055)$. The null hypothesis cannot therefore be rejected for the UK case. The independent variables individually had neither significant effect on support for nuclear power (Table 2.). Most variance in dependent variable, but still negligible, was explained by trust in Government (15\%) and trust in NGO's (11\%).

Table 2. Linear Regression Statistics for each independent variable.

\begin{tabular}{|c|c|c|c|c|}
\hline \multicolumn{2}{|c|}{ F-statistics } & $\mathrm{p}$-value & $\mathrm{R}^{2}$ & $\operatorname{adj} R^{2}$ \\
\hline TrustGov & 1.507 & 0.242 & 0.104 & 0.035 \\
\hline TrustBus & 0.273 & 0.611 & 0.021 & -0.055 \\
\hline TrustNGO & 0.699 & 0.418 & 0.051 & -0.021 \\
\hline TrustMedia & 0.237 & 0.634 & 0.018 & -0.057 \\
\hline
\end{tabular}

\section{USA results}

The overall relationship of the US data can be seen in figure 6. Multicollinearity was examined and Trust in NGO's and and Trust in Businesses were find to be moderately correlated. The correlation coefficients between independent variables are displayed in Table 3.

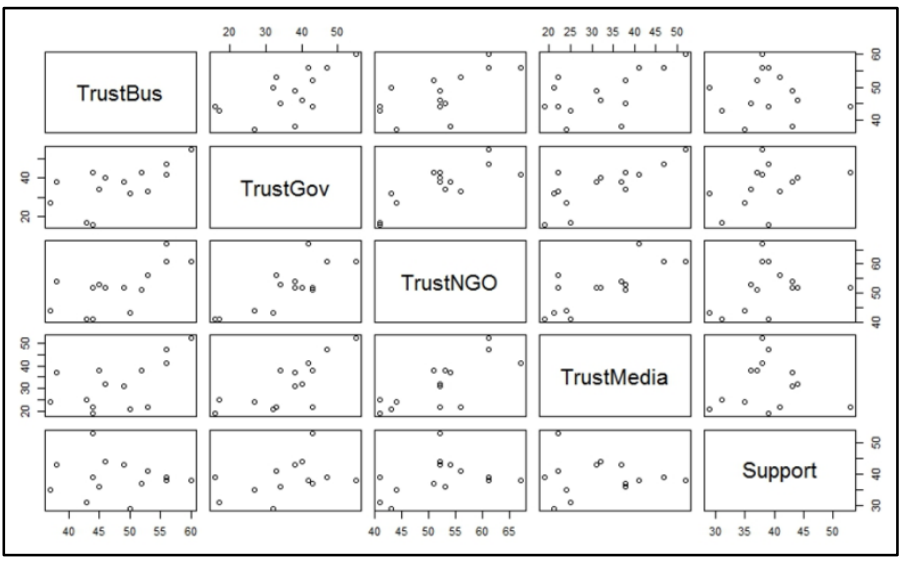

Figure 6. Scatterplots of correlations between USA variables.

Table 3. Correlation coefficients of USA independent variables.

\begin{tabular}{lccc}
\hline & TrustGov & TrustBus & TrustNGO \\
\hline TrustGov & - & - & - \\
TrustBus & -0.09 & - & - \\
TrustNGO & -0.11 & -0.56 & - \\
TrustMedia & -0.18 & -0.26 & -0.46 \\
\hline
\end{tabular}

The results of multiple regression for US data indicated that the four predictors explained $55.8 \%$ of the variance $\left(\mathrm{R}^{2}=0.558\right.$ and adjusted $\left.\mathrm{R}^{2}=0.382\right)$ but again the significance was not confirmed $(\mathrm{F}(4,10)$ $=3.164$ and $\mathrm{p}=0.0635)$. The null hypothesis cannot be rejected neither for the US case. The individual independent variables effects did not prove to have significant effect on support for nuclear power (Table 4). Most variance in dependent variable, but still negligible, was explained by trust in Government (10\%).

Table 4. Statistics for Linear Regression of each variable.

\begin{tabular}{lcclc}
\hline \multicolumn{2}{c}{ F-statistics } & p-value & \multicolumn{1}{c}{$\mathrm{R}^{2}$} & adj $\mathrm{R}^{2}$ \\
\hline TrustGov & 2.164 & 0.167 & 0.153 & 0.082 \\
TrustBus & 0.097 & 0.761 & 0.008 & -0.074 \\
TrustNGO & 1.518 & 0.242 & 0.112 & -0.038 \\
TrustMedia & 0.0005 & 0.983 & $3.93 \mathrm{e}-05$ & -0.057 \\
\hline
\end{tabular}

\section{DISCUSSION}

Structural Equation modelling and Multiple Regression Analysis were used to evaluate the relationship between four independent and one dependent variable. The four independent variables were Trust in Government, Trust in Media, Trust in NGO's and Trust in Businesses, the dependent variable was Support for Nuclear power. Structural Equation modelling results did not support the rejection of null hypothesis that Trust in Institutions has a significant effect on Support for nuclear power. The sample size was very small and could have affected the outcome as SEM is known to be a technique for large sample sizes. The fact that chi- 
square showed a good fit for both - UK and USA models but other indices proved a bad fit can suggest bad requisites of used data. Bigger sample size is a need for further studies as data available for this study did not have robust enough background for SEM.

Multiple Regression analysis seemed to be a better technique for small sample size data evaluation. Although significance of effect of combination of independent variables on dependent variable was not proved, $60 \%$ of variance in dependent variable was explained in UK case and 55\% in case of USA by combination of independent variables. When investigated individually, the most variance, although very small part, was in both cases explained by Trust in Government (10\% in the USA and $15 \%$ in the UK) followed in both cases by trust in NGO's (5\% in the USA and $11 \%$ in the UK). The results might be influenced by small sample of data and inconsistency in data sources as well as absence of dependent variable values for some years. Long term historical longitudinal data is difficult to acquire and therefore this study is not as extensive as originally intended. The availability of more data (longer time period or more countries) could have significant influence on results outcome and conclusions. Further data search will be conducted and results re-evaluated when more robust data available.

\section{CONCLUSIONS}

In this study the effect of Trust in institutions on Support for nuclear power in UK and USA was investigated. The null hypothesis is that Trust in institutions has no influence on public support for nuclear power. Data for this study were acquired from polls and surveys performed by worldwide research and polling companies. The final sample size was much smaller than originally intended as many data were not available. Structural Equation modelling and Multiple Regression analysis were used to evaluate the data. Structural Equation modelling does not prove to be a good technique for such a small sample size. The null hypothesis could not be rejected based on SEM results and the hypothesised model showed questionable fit as some fit indices showed good fit and some very poor fit. Results from Multiple Regression analysis did not allow rejecting the null hypothesis neither as results for both countries were not significant. Although significance of Trust in institutions on public support for nuclear power was not proved, the variance in Support for nuclear was explained by combination of independent variables by $60 \%$ in UK and by $55 \%$ in USA. The fact that explained variance was quite high but results did not prove to be significant requires further investigation. Further data search is required so results can be re-evaluated and compared when more robust data are available.

\section{REFERENCES}

Edelman. (2016). Edelman TRUST BAROMETERâ,, ф Archive. [online] Available at: http://www.edelman.com/insights/intellectualproperty/edelman-trust-barometer-archive/ [Accessed 22 Feb. 2016].

Gallup, I. (2015). U.S. Support for Nuclear Energy at 51\%. [online] Gallup.com. Available at: http://www.gallup.com/poll/182180/support-nuclearenergy.aspx [Accessed 24 Mar. 2016].

Goodfellow, M., Dewick, P., Wortley, J. and Azapagic, A. (2015). Public perceptions of design options for new nuclear plants in the UK. Process Safety and Environmental Protection, 94, pp.72-88.

Hooper, D., Coughlan, J., Mullen, M. (2008). Structural Equation Modelling: Guidelines for Determining Model Fit. Electronic Journal of Business Research Methods, 6(1), 53-60

Ipsos-mori.com. (2011). Ipsos MORI | Poll | Support for Nuclear Power - trend. [online] Available at: https://www.ipsos-

mori.com/researchpublications/researcharchive/2618/Su pport-for-Nuclear-Power-trend.aspx [Accessed 10 Mar. 2016].

Kim, Y., Kim, W. and Kim, M. (2014). An international comparative analysis of public acceptance of nuclear energy. Energy Policy, 66, pp.475-483.

Liu, C., Zhang, Z. and Kidd, S. (2008). Establishing an objective system for the assessment of public acceptance of nuclear power in China. Nuclear Engineering and Design, 238(10), pp.2834-2838.

Nuclear Energy Agency, (2010). Public Attitudes to Nuclear Power. Paris: Organisation for Economic Co-operation and Development.

Peters, R., Covello, V. and McCallum, D. (1997). The Determinants of Trust and Credibility in Environmental Risk Communication: An Empirical Study. Risk Analysis, 17(1), pp.43-54.

Pidgeon, N., Lorenzoni, I. and Poortinga, W. (2008). Climate change or nuclear powerâ€'No thanks! A quantitative study of public perceptions and risk framing in Britain. Global Environmental Change, 18(1), pp.69-85.

The Guardian, (2015). Public support for UK nuclear and shale gas falls to new low. [online] Available at: http://www.theguardian.com/environment/2015/aug/04/p ublic-support-for-uk-nuclear-shale-gas-falls-new-low [Accessed 11 Mar. 2016]. 